\title{
AVALIAÇÃO DA HIPERALGESIA E ALTERAÇÕES HISTOLÓGICAS DO GÂNGLIO DA RAIZ DORSAL INDUZIDAS PELO NÚCLEO PULPOSO
}

\author{
EVALUATION OF HYPERALGESIA AND HISTOLOGICAL CHANGES \\ OF DORSAL ROOT GANGLION INDUCED BY NUCLEUS PULPOSUS
}

André Luiz de Souza Grava', Luiz Fernando Ferrari' ${ }^{2}$, Carlos Amílcar Parada ${ }^{3}$, Helton Luiz Aparecido Defino ${ }^{4}$

\section{RESUMO}

Objetivo: Avaliar a hiperalgesia e as alterações histológicas induzidas pelo contato do gânglio da raiz dorsal com o núcleo pulposo. Métodos: Foram utilizados 20 ratos Wistar, divididos em dois grupos experimentais. Em um dos grupos um fragmento do NP autólogo retirado da região sacrococcígea foi colocado sobre os gânglios da raiz dorsal de L5, e no outro grupo (controle) um fragmento de tecido adiposo foi colocado sobre o gânglio da raiz dorsal de L5. A hiperalgesia mecânica e térmica foi avaliada no terceiro dia, na primeira, terceira, quinta e sétima semanas de pós-operatório. O gânglio da raiz dorsal de L5 foi retirado na primeira, terceira, quinta e sétima semanas de pós-operatório para estudo histológico por meio da coloração com HE e estudo histoquímico (marcação específica para iNOS). Resultados: Foi observada hiperalgesia térmica e mecânica de maior intensidade no grupo de animais em que o NP foi colocado em contato com o GRD, e nesse grupo o estudo histológico evidenciou alterações dos tecidos do gânglio da raiz dorsal, caracterizadas por processo inflamatório e degeneração axonal. As alterações histopatológicas dos tecidos do gânglio da raiz dorsal apresentaram intensidade crescente com o aumento do período de observação, apresentando correlação com a manutenção da hiperalgesia observada na avaliação comportamental. A imunohistoquímica com marcação específica para iNOS demonstrou, no grupo de animais em que o núcleo pulposo foi colocado em contato com o gânglio da raiz dorsal, aumento da expressão dessa enzima nos núcleos das células inflamatórias (células da glia) ao redor

\section{ABSTRACT}

Objective: To evaluate hyperalgesia and histological changes of dorsal root ganglia induced by nucleus pulposus (NP) contact. Methods: Twenty Wistar rats were used, divided into two experimental groups. In one of the groups, a fragment of the autologous NP was removed from the sacroccocigeal region and deposited on the L5 dorsal root ganglia. In the control group, the NP was removed from the sacrococcygeal region, L5 dorsal root ganglia were exposed and covered by a piece of adipous fat tissue. Hyperalgesia was evaluated by the von Frey electronic test and Hargreaves test, and histological changes of the dorsal root ganglia by HE staining and immunohistochemistry using iNOS. The evaluation of hyperalgesia and histological changes of the dorsal root ganglia were performed on the third postoperative day and after 1, 3, 5, and 7 weeks. Results: NP induced higher intensity mechanical and thermal hyperalgesia. Dorsal root ganglia in contact with nucleus pulposus presented histological changes and the intensity of these changes were proportional to the length of time in contact. The expression of iNOS was higher in the glial cells in contact with the nucleus pulposus. Conclusion: The contact of nucleus pulposus with dorsal root ganglia induced histologi-

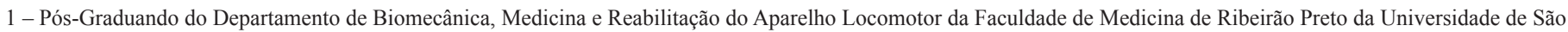
Paulo - USP - Ribeirão Preto (SP), Brasil.

2 - Pós-Graduando do Departamento de Farmacologia da Faculdade de Medicina de Ribeirão Preto da Universidade de São Paulo - USP - Ribeirão Preto (SP), Brasil.

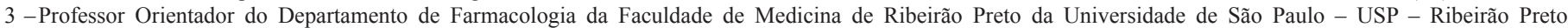
(SP), Brasil.

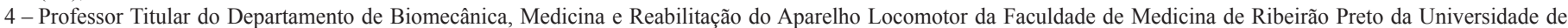
São Paulo - USP - Ribeirão Preto (SP), Brasil.

Trabalho realizado na Faculdade de Medicina de Ribeirão Preto - USP - Ribeirão Preto (SP) Brasil

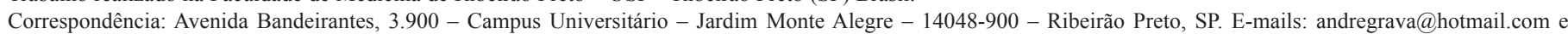

hladefin@fmrp.usp.br 
dos neurônios. Conclusão: O contato do núcleo pulposo com o gânglio da raiz dorsal de L5 induziu a hiperalgesia mecânica e térmica e provocou alterações histológicas dos componentes do gânglio da raiz dorsal. As alterações foram caracterizadas por processo inflamatório e degenerativo das estruturas do gânglio da raiz dorsal e apresentaram aumento da intensidade nos períodos mais longos de observação.

Descritores - Coluna Vertebral; Disco Intervertebral; Dor Lombar; Hiperalgesia; Deslocamento do Disco Intervertebral; Ratos Wistar cal changes and mechanical and thermal hyperalgesia. These changes were more intense after longer period of evaluation.

Keywords - Spine; Intervertebral Disk; Low Back Pain; Hyperalgesia; Intervertebral Disk Displacement; Rats Wistar

\section{INTRODUÇÃO}

A sintomatologia causada pela hérnia de disco está relacionada com a compressão mecânica das raízes nervosas lombares ${ }^{(1-3)}$ e pelo processo inflamatório provocado pelos componentes do núcleo pulposo. A compressão das raízes nervosas ocorre pelo extravasamento do conteúdo do disco intervertebral lesado para o interior do canal vertebral, que é um espaço rígido e limitado. O processo inflamatório relacionado com a hérnia de disco lombar é causado pelo contato dos componentes bioquímicos do núcleo pulposo em contato com o tecido nervoso $^{(4-7)}$. O núcleo pulposo é uma estrutura gelatinosa presente no interior do disco intervertebral e circundado pelo anel fibroso, praticamente acelular, não vascularizado, desprovido de vasos linfáticos e composto por proteoglicanas e água. Uma vez que não possui contato com a circulação sistêmica após a embriogênese, é reconhecido como corpo estranho quando exposto ao sistema imune, desencadeando resposta inflamatória caracterizada por infiltrado de neutrófilos, macrófagos e células $\mathrm{T}$ e $\mathrm{B}$, ao redor do disco intervertebral herniado ${ }^{(2,8)}$. Corroborando os estudos que evidenciaram o componente inflamatório na fisiopatologia dos sintomas da hérnia de disco, foi também demonstrada a presença de citocinas pró-inflamatórias como interleucina-1 $\beta$ (IL-1 $\beta$ ), interleucina-6 (IL-6), interleucina-8 (IL-8) e fator de necrose tumoral- $\alpha$ (TNF $\alpha)$, nos pacientes com hérnia de disco lombar ${ }^{(9,10)}$.

Tem sido relatado que o núcleo pulposo possui a capacidade de provocar alterações na estrutura do gânglio da raiz dorsal, caracterizadas por processo inflamatório e apoptose celular ${ }^{(11,12)}$. O objetivo do estudo foi avaliar experimentalmente a hiperalgesia mecânica e térmica, e as alterações histológicas do gânglio da raiz dorsal induzidas pelo contato com o núcleo pulposo.

\section{MATERIAL E MÉTODOS}

Foram utilizados 20 ratos Wistar, machos com peso entre 220 e $250 \mathrm{~g}$, fornecidos pelo Biotério Central da Faculdade de Medicina de Ribeirão Preto-USP. Antes da realização do experimento, os animais permaneciam dois dias no biotério local para a sua aclimatação em gaiolas de $40 \times 60 \times 20 \mathrm{~cm}$, com o máximo de seis animais por gaiola, sob condições controladas de temperatura (22 a $\left.25^{\circ} \mathrm{C}\right)$ e ciclo claro/escuro $(12 \times 12 \mathrm{~h})$ com livre acesso à água e comida. $\mathrm{O}$ projeto de pesquisa foi aprovado pelo comitê local de ética e experimentação em animais e conduzido de acordo com as normas internacionais de ética para a utilização de animais de laboratório.

Para a realização do procedimento cirúrgico, os animais foram anestesiados por meio da injeção intraperitoneal (i.p.), com solução de cetamina (Ketamina Agener ${ }^{\circledR}$ a $10 \%$ ), na dose de $0,1 \mathrm{ml}$ por $100 \mathrm{~g}$ de peso corpóreo dos ratos, xilazina (Anesedan ${ }^{\circledR}$ a $2 \%$ ), na dose de $0,07 \mathrm{ml}$ por $100 \mathrm{~g}$ de peso e fentanil (Fentanest ${ }^{\circledR}$ a $5 \%$ ) na dose de $0,001 \mathrm{ml}$ por $100 \mathrm{~g}$ de peso. Em todos os animais foi administrada, no pré-operatório, dose única de Pentabiótico Veterinário (benzilpenicilina benzatina) 600.000UI, benzilpenicilina procaína $300.000 \mathrm{UI}$, benzilpenicilina potássica $300.000 \mathrm{UI}$, sulfato de dihidroestreptomicina $250 \mathrm{mg}$ e sulfato de estreptomicina $250 \mathrm{mg}$ (Pentabiótico Veterinário Pequeno Porte ${ }^{\circledR}$ ) por via intramuscular, na dose de $0,1 \mathrm{ml}$ para cada $100 \mathrm{~g}$ de peso corpóreo do rato. Para o procedimento de retirada dos gânglios da raiz dorsal para o estudo histológico foi utilizada anestesia intraperitonial com solução de hidrato de cloral a 4\% na dose de $1 \mathrm{ml}$ por $100 \mathrm{~g}$ de peso corpóreo.

O modelo experimental de hérnia de disco foi utilizado de acordo com o método descrito por Grava et al ${ }^{(13)}$, que consiste na retirada de fragmento do núcleo pulposo da região sacrococcígea, seguida da sua aposição 
sobre o gânglio da raiz dorsal da quinta raiz lombar (Figura 1). A retirada do núcleo pulposo (NP) do disco intervertebral foi realizada na região sacrococcígea (base da cauda do rato) por meio de incisão na linha média da região de transição entre a quarta vértebra sacral e a primeira vértebra coccígea. O disco intervertebral foi bilateralmente exposto e, por meio de incisão transversal sobre o anel fibroso, o NP foi retirado. O material gelatinoso do NP foi coletado, pesado em balança de precisão (peso de 4 a $5 \mathrm{mg}$ em média) e, em seguida, depositado no local determinado para o estudo (dura-máter, GRD ou raiz nervosa). Após o procedimento, a ferida cirúrgica foi suturada em um único plano, abrangendo a fáscia muscular e a pele. A cirurgia para a colocação do conteúdo do NP sobre os tecidos nervosos foi realizada com o auxílio de lente ótica, com magnificação do campo de observação de 10 vezes. Por meio de laminectomia parcial hemilateral à direita e retirada do processo transverso vertebral no nível estabelecido, as estruturas (dura-máter, GRD ou raiz nervosa) eram expostas e o conteúdo do NP, depositado.
Nos animais do grupo-controle foi realizado o mesmo procedimento para a retirada do núcleo pulposo da região sacrococcígea e exposição do gânglio da raiz dorsal de L5, tendo sido colocado fragmento de tecido adiposo sobre o gânglio da raiz dorsal de L5.

Foram formados dois grupos experimentais com 10 animais em cada grupo. Ambos os grupos foram submetidos à cirurgia para a retirada do fragmento do núcleo pulposo do disco intervertebral da região sacrococcígea, sendo o conteúdo do núcleo pulposo colocado sobre o L5-GRD no grupo I, e no grupo II (controle) colocado fragmento de tecido adiposo com tamanho semelhante ao fragmento de núcleo pulposo utilizado no grupo I.

Após a realização do procedimento cirúrgico, os animais eram avaliados por meio de testes comportamentais para a avaliação da hiperalgesia mecânica (teste de von Frey eletrônico) ${ }^{(14)}$ e térmica (teste de Hargraves) ${ }^{(15)}$ no terceiro dia, e na primeira, terceira, quinta e sétima semanas após a realização do procedimento cirúrgico para a indução dos sintomas inflamatórios da hérnia de disco. A avaliação da hiperalgesia era realizada por

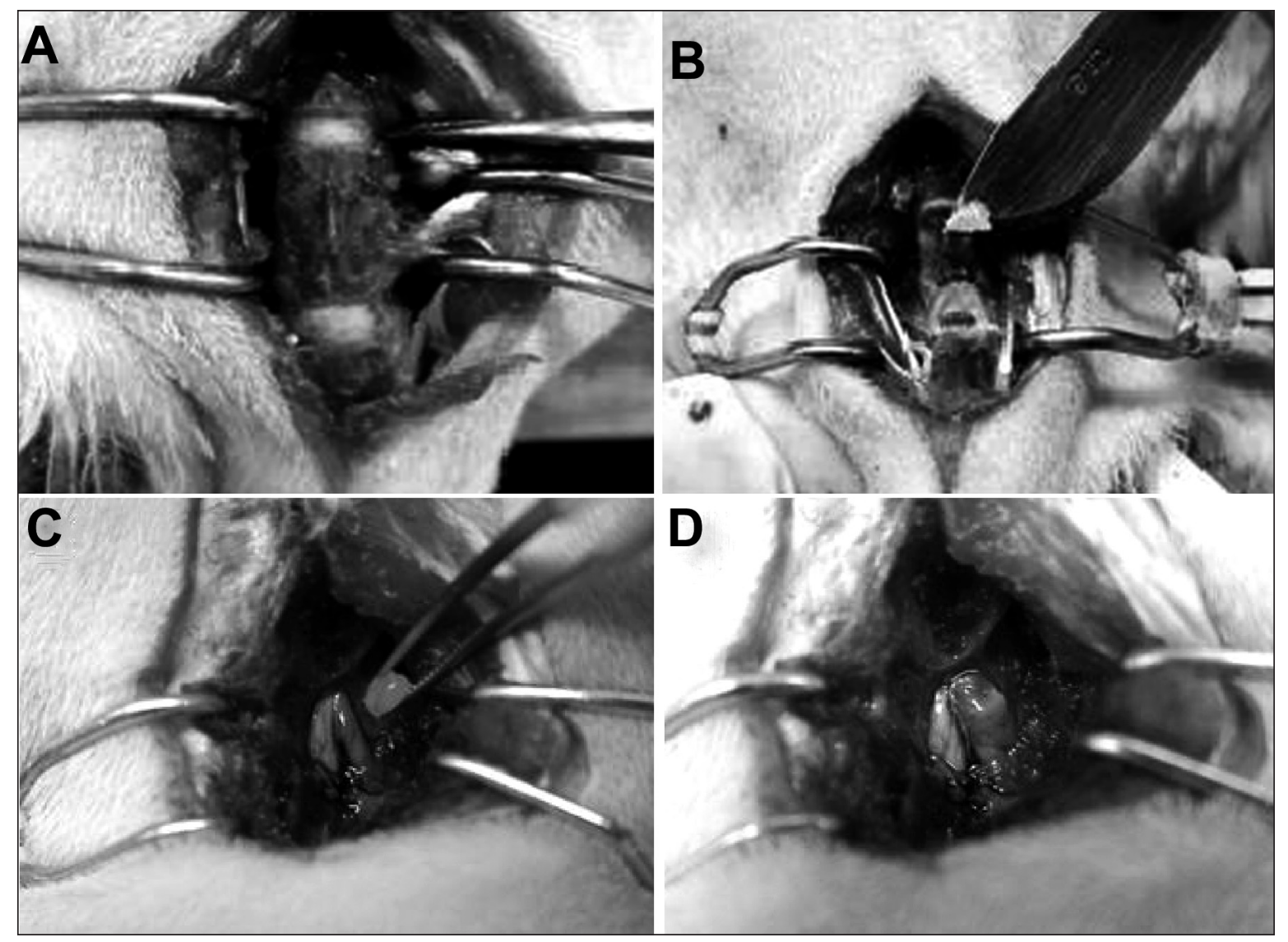

Figura 1 - Fotografias ilustrando o procedimento cirúrgico para a colocação do fragmento do núcleo pulposo em contato com o gânglio da raiz dorsal de L5. A) abordagem cirúrgica da região sacrococcígea para a retirada do fragmento do núcleo pulposo. B, C e D) Sequência cirúrgica da exposição do gânglio da raiz dorsal de L5 e posterior colocação do núcleo pulposo sobre o tecido nervoso. 
avaliador independente, que não participou das cirurgias dos animais e não possuía informações relacionadas com o grupo experimental ou procedimento realizado.

\section{Teste de pressão crescente na pata de ratos (von Frey eletrônico)}

A hiperalgesia mecânica foi avaliada por meio do teste de pressão crescente na pata de ratos, denominado de teste von Frey eletrônico (tenocicepção) ${ }^{(14)}$. O método consiste no uso de um anestesiômetro eletrônico (modelo 1601C, Life Science Instruments ${ }^{\circledR}$ ), o qual possui um transdutor de força conectado a um contador digital de força expressa em gramas (g). A precisão do aparelho é de $0,1 \mathrm{~g}$ e o mesmo é calibrado para registrar força máxima de $150 \mathrm{~g}$, mantendo a precisão de $0,1 \mathrm{~g}$ até a força de $80 \mathrm{~g}$. O contato do transdutor de força com a pata é realizado por meio de uma ponteira descartável de polipropileno com $0,5 \mathrm{~mm}$ de diâmetro adaptada ao transdutor. Os animais são colocados em caixas de acrílico, medindo $12 \times 20 \times 17 \mathrm{~cm}$, cujo assoalho consiste de uma rede de malha igual a $5 \mathrm{~mm}^{2}$, constituída de arame não maleável de $1 \mathrm{~mm}$ de espessura, durante 15 minutos antes do experimento, para adaptação ao ambiente. Espelhos posicionados $25 \mathrm{~cm}$ abaixo das caixas de experimentação facilitam a visualização das plantas das patas dos animais. $\mathrm{O}$ experimentador aplica, por entre as malhas da rede, força linearmente crescente no centro da planta da pata do rato até que o animal produza uma resposta de retirada e "sacudida" da pata estimulada. Os estímulos são repetidos até seis vezes, em geral até que o animal apresente três medidas similares com uma nítida resposta de "sacudida" após a retirada da pata.

\section{Teste de hiperalgesia térmica de Hargreaves (plantar test)}

A avaliação da hiperalgesia térmica foi realizada por meio do teste plantar de Hargreaves et a ${ }^{(15)}$. Esse teste consiste no aquecimento, por meio de fonte de luz infravermelha dirigida, da região plantar da pata traseira do rato, até que o animal apresente o comportamento da retirada da pata ou o aquecimento da pata atinja o limite de tempo predeterminado (tempo de corte de 12 segundos).

Os animais são colocados em compartimentos de acrílico individual e posicionados sobre uma superfície de vidro especial, que permite a passagem de forma homogênea da luz e do calor, durante cinco minutos, para adaptação ao ambiente. Após esse período, uma fonte de luz infravermelha, colocada sob cada uma das patas traseiras do animal, é acionada juntamente com um cronômetro eletrônico, até que o animal retire a pata, quando, então, a fonte de luz e o relógio param automaticamente.

São realizadas três medidas com intervalo de tempo de 5 a 10min. As medidas de latência de retirada da pata são então expressas como avaliações percentuais relativas às patas-controle (contralaterais) em cada tempo de observação. Na situação em que o animal não apresenta reação, é estipulado um tempo limite máximo de corte do experimento de 12 segundos para a preservação da sua integridade física.

Foram sacrificados dois animais de cada grupo experimental na primeira, terceira, quinta e sétima semanas após a realização do procedimento cirúrgico, com a finalidade de retirar os gânglios da raiz dorsal de L5 para a realização do estudo histológico.

Os gânglios da raiz dorsal de L5 foram retirados de ambos os lados. O gânglio do lado contralateral ao operado foi utilizado como controle do estudo histológico. O material foi processado para estudo histológico e realizada a coloração por meio do HE (microscopia de luz) e Hoescht (imunohistoquímica e observação em microscópio de fluorescência).

A comparação dos resultados dos testes comportamentais foi realizada por meio de estudo estatístico por meio da análise de variância multivariada (MANOVA), seguida do teste $t$ de Student com desigualdade de Bonferroni, tendo sido estabelecido o nível de significância de $p<0,05$.

\section{RESULTADOS}

A avaliação da intensidade da hiperalgesia mecânica e térmica nos diferentes períodos de avaliação está representada na Figura 2, e ilustra a diferença estatística observada durante todo o período de observação entre os dois grupos experimentais, evidenciando a influência do contato do núcleo pulposo em contato com o gânglio da raiz nervosa da quinta raiz lombar na indução da hiperalgesia. No grupo de animais em que o núcleo pulposo foi colocado em contato com o gânglio da raiz dorsal de L5 foi observado pequena redução da intensidade da hiperalgesia mecânica e térmica ao longo do período de observação, enquanto que nos animais que tiveram tecido adiposo depositado sobre o gânglio da raiz dorsal, a redução da intensidade da hiperalgesia foi maior.

A avaliação histológica do gânglio da raiz dorsal de L5 em contato com o fragmento do núcleo pulposo evidenciou a presença de processo inflamatório, caracterizado por proliferação das células de Schwann ao redor dos 

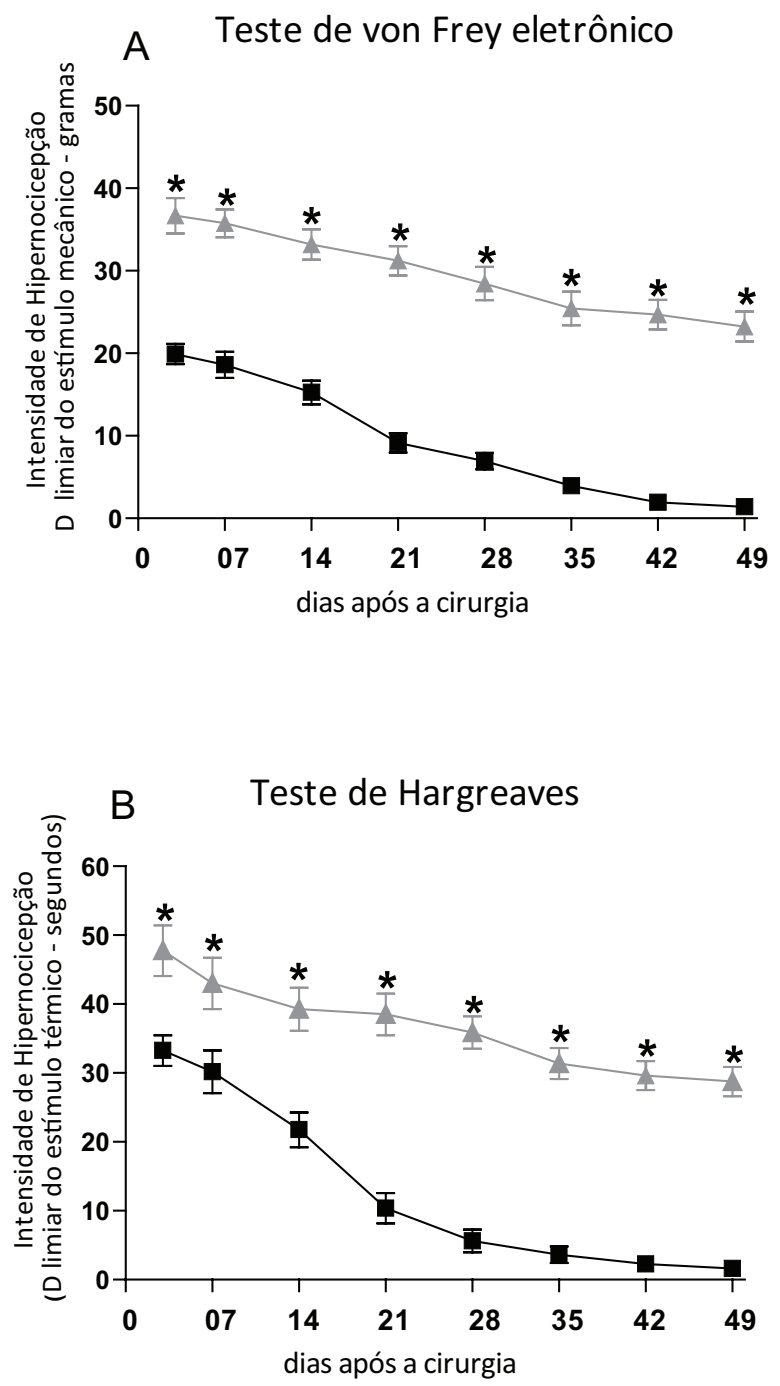

$\rightarrow$ Sham operado $\rightarrow-$ Hérnia GRD L5/L6

Figura 2 - Intensidade de hiperalgesia mecânica (teste de von Frey eletrônico) e térmica (testes de Hargreaves) nos grupos experimentais. O asterisco $\left({ }^{*}\right)$ indica a diferença estatística (teste $t$ de Student para dados não pareados $-p<0,05$ ).

neurônios, além de discretas alterações degenerativas dos corpos neuronais de alguns neurônios do gânglio, caracterizadas por núcleos excêntricos e alargamento citoplasmático, diferente dos gânglios utilizados como controle. Os gânglios controle apresentavam núcleo na região central, citoplasma homogêneo e poucas células satélites. As alterações observadas indicam a ocorrência de processo degenerativo progressivo de alguns neurônios, que evolui para processo inflamatório de pequena intensidade na primeira semana (Figura 3), passando por um estágio intermediário na terceira e quinta semanas (Figura 4), em que se observa intenso processo inflamatório, com maior proliferação das células da glia, citoplasma de aspecto rendilhado e presença de alguns neurônios apoptóticos.

A partir da quinta semana foi observado processo degenerativo de maior intensidade, caracterizado por células com núcleos excêntricos ou picnóticos, intensa proliferação e adesão de células aos neurônios (Figura 4).

Após sete semanas, foi observado aspecto irreversível de degeneração, induzido pelo processo inflamatório, evidenciando núcleos apoptóticos de neurônios e aumento do número de células da glia (Figura 5). Foi observada intensa coloração das lâminas no grupo em que o núcleo pulposo ficou em contato com o gânglio da raiz dorsal, destacando a presença de muitos núcleos de células inflamatórias (células da glia) ao redor dos neurônios, muito diferente do observado no grupo controle (Figura 5).

A imunohistoquímica com marcação específica para iNOS (Figura 5) demonstrou aumento da expressão dessa enzima nos núcleos das células inflamatórias (células da glia) ao redor dos neurônios, contrastando com as observações do grupo controle.

Alterações histopatológicas dos tecidos do gânglio da raiz dorsal, caracterizadas principalmente por processo inflamatório e degeneração axonal foram observadas, tendo sido esse processo induzido pelo contato do núcleo pulposo com o gânglio da raiz dorsal, e apresentando crescente intensidade temporal e correlação com a manutenção da hiperalgesia observada na avaliação comportamental.

\section{DISCUSSÃO}

Um novo campo de estudo e pesquisa surgiu após a observação de que a colocação do núcleo pulposo em contato com os elementos nervosos e sem compressão mecânica das estruturas nervosas induzia alterações estruturais e funcionais das estruturas nervosas em contato ${ }^{(6)}$. Embora o exato mecanismo envolvido na gênese da hiperalgesia produzida pelo contato do núcleo pulposo com as estruturas nervosas não seja totalmente conhecido, os resultados de diferentes estudos evidenciam a sua propriedade de induzir alterações inflamatórias dos tecidos ${ }^{(8,16)}$. Em estudo realizado para o desenvolvimento de modelo experimental, observamos que o contato do núcleo pulposo com a dura-máter, raiz nervosa ou gânglio da raiz dorsal provocava o aparecimento de hiperalgesia mecânica e térmica ${ }^{(13)}$. Foi observado ainda que a utilização do gânglio da raiz dorsal 

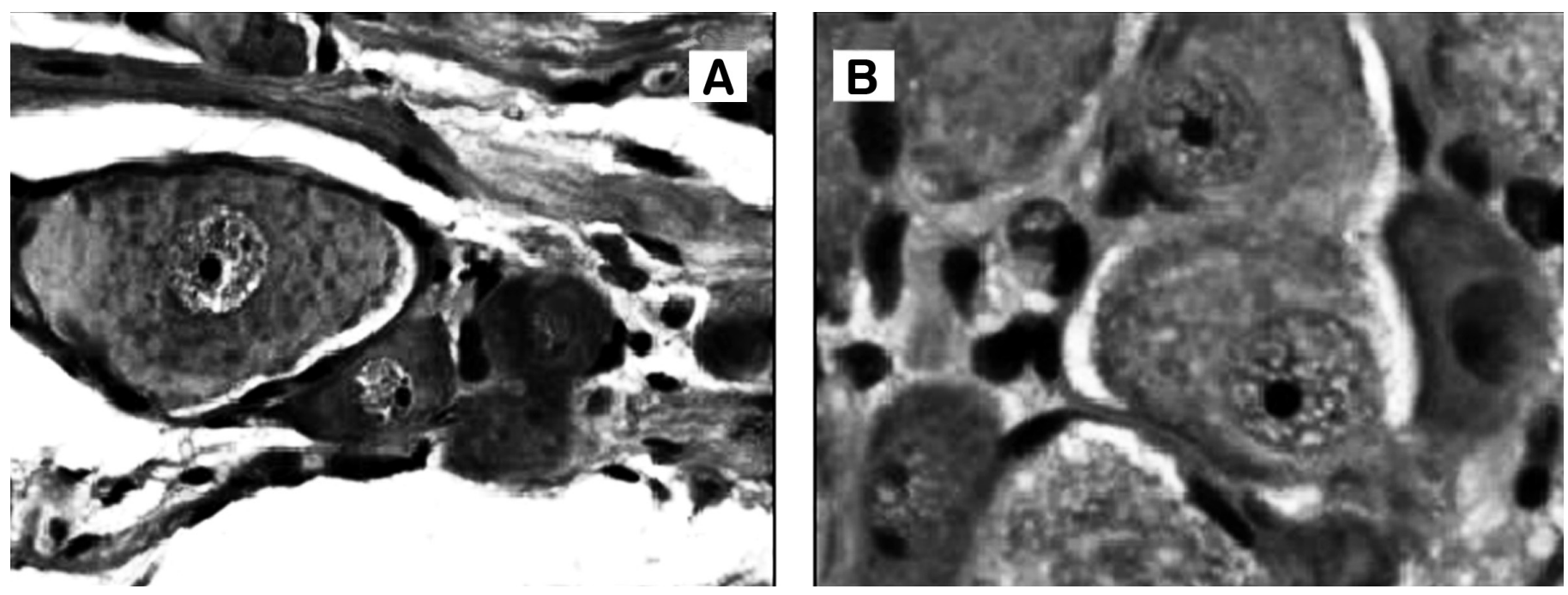

Figura 3 - Fotomicrografia de corte histológico do gânglio da raiz dorsal de L5 (aumento de 40x, coloração com HE). A) Gânglio em contato com o núcleo pulposo e coletado uma semana após o procedimento cirúrgico. Observar a proliferação de células de Schwann ao redor dos neurônios que apresentam núcleos excêntricos e alargamento citoplasmático. B) Gânglio de animal controle. Observar o núcleo na região central, citoplasma homogêneo e presença de poucas células satélites.

de L5 para a aposição do fragmento do núcleo pulposo produzia a maior intensidade de hiperalgesia mensurada pelos métodos utilizados, tendo sido esse o motivo para a escolha dessa estrutura para a realização do estudo.

Têm sido relatadas alterações da estrutura do DRG após o seu contato com o núcleo pulposo. As alterações podem ser observadas logo após três horas do contato do NP com o DRG, e são caracterizadas pela deformação do núcleo celular, apoptose e processo inflamatório ${ }^{(11,12)}$.
As alterações observadas em nosso estudo corroboram os resultados descritos na literatura ${ }^{(17-19)}$, e foram caracterizadas pela presença de processo inflamatório com proliferação de células de Schwann ao redor dos neurônios, alterações degenerativas dos corpos neuronais, tendo sido essas alterações progressivas com o decorrer do tempo. No período mais tardio de avaliação, as alterações apresentavam características de irreversibilidade e degeneração induzida pelo processo inflamatório.
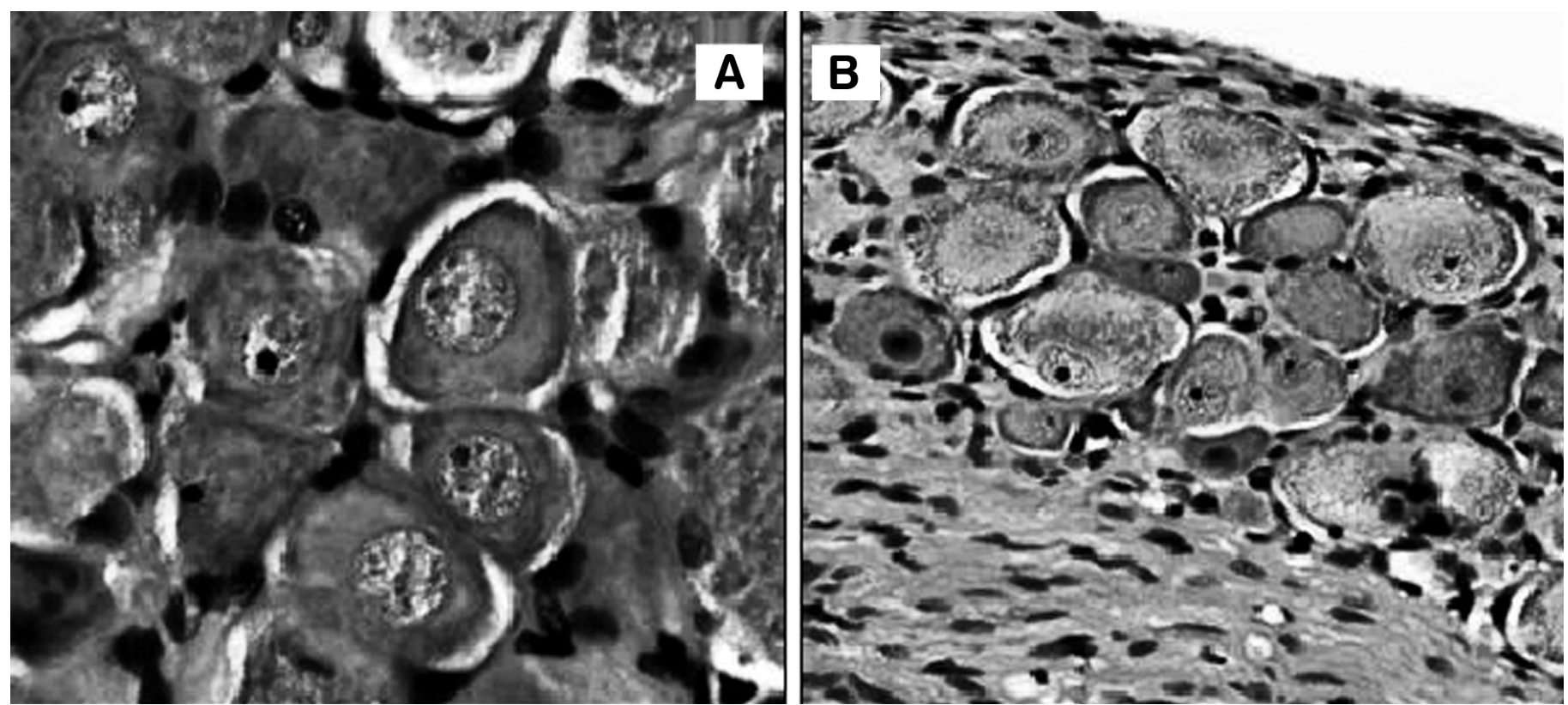

Figura 4 - Fotomicrografia de gânglios da raiz dorsal de L5 coletados após três semanas (A) e cinco semanas (B). A) Observar o intenso processo inflamatório com maior proliferação de células da glia, citoplasma de aspecto rendilhado e presença de alguns neurônios apoptóticos (aumento 40x, coloração HE). B) Processo degenerativo mais acentuado, caracterizado por células com núcleos excêntricos ou picnóticos. Intensa proliferação e adesão das células da glia ao redor dos neurônios (aumento 20x, coloração HE). 

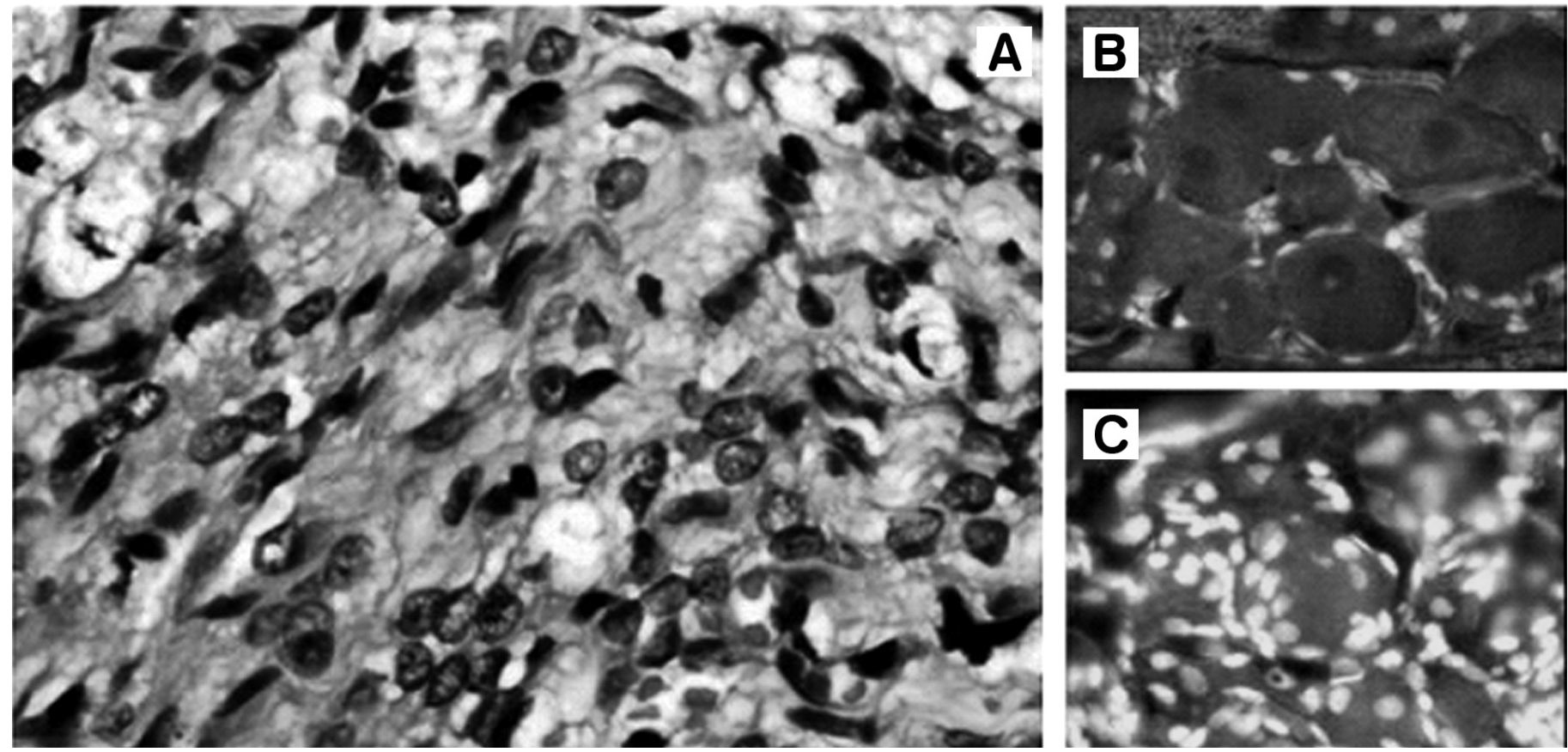

Figura 5 - Fotomicrografia de gânglio da raiz dorsal de L5 coletado após sete semanas da cirurgia. A) Observar o aspecto irreversível da degeneração induzida pelo processo inflamatório do gânglio (aumento de 40x, coloração HE). B e C) Cortes histológicos corados por Hoescht e examinados à microscopia de fluorescência, evidenciando a marcação para iNOS nos núcleos de neurônios e células da glia. Animal do grupo controle (B) e animal com gânglio da raiz dorsal em contato com o núcleo pulposo (B) apresentando aumento do número das células da glia.

O aumento da expressão da enzima óxido nítrico sintase no núcleo das células inflamatórias ao redor dos neurônios sugere o aumento da produção local do óxido nítrico no local da hérnia de disco. O óxido nítrico (NO) é formado a partir da oxidação do nitrogênio terminal do aminoácido L-arginina pela ação da enzima óxido nítrico sintase (NOS). Existem pelo menos três isoformas bem definidas dessa enzima: NOS neural (descrita inicialmente nos neurônios); NOS induzida (presente nos leucócitos ativados) e NOS endotelial (primeiramente observada nas células endoteliais) ${ }^{(20)}$. A atividade da enzima induzida (iNOS) é capaz de produzir NO em concentração micromolecular, em comparação à enzima constitutiva que produz esse mediador apenas em concentração nanomolar. A síntese de NOS induzida pode ativada por citocinas, como o TNF- $\alpha$, IL-1ß, interferon- $\alpha, \beta$ e $\gamma$, liberadas durante o processo inflamatório ou infeccioso ${ }^{(21,22)}$. A origem do NO no processo inflamatório não é clara, podendo decorrer das células endoteliais, neutrófilos e macrófagos ${ }^{(23)}$. O NO pode modular a resposta inflamatória atuando como substância pró-inflamatória ${ }^{(24)}$ e o papel pró-inflamatório do $\mathrm{NO}$ produzido pela atividade da enzima induzida (iNOS) também foi demonstrado(25).

\section{CONCLUSÕES}

O contato do núcleo pulposo com o gânglio da raiz dorsal de L5 resultou em alterações histológicas dos tecidos do gânglio, caracterizadas por processo inflamatório e degeneração axonal. As alterações histopatológicas dos tecidos do gânglio da raiz dorsal apresentaram intensidade crescente com o aumento do período de observação, apresentando correlação com a manutenção da hiperalgesia observada na avaliação comportamental.

\section{REFERÊNCIAS}

1. Cornefjord M, Sato K, Olmarker K, Rydevik B, Nordborg C. A model for chronic nerve root compression studies. Presentation of a porcine model for controlled, slow-onset compression with analyses of anatomic aspects, compression onset rate, and morphologic and neurophysiologic effects. Spine (Phila Pa 1976). 1997;22(9):946-57.

2. Kawakami M, Weinstein JN, Chatani K, Spratt KF, Meller ST, Gebhart GF. Experimental lumbar radiculopathy. Behavioral and histologic changes in a model of radicular pain after spinal nerve root irritation with chromic gut ligatures in the rat. Spine (Phila Pa 1976). 1994;19(16):1795-802.

3. Kobayashi S, Uchida K, Yayama T, Takeno K, Miyazaki T, Shimada S, et al. Motor neuron involvement in experimental lumbar nerve root compression: a light and electron microscopic study. Spine (Phila Pa 1976). 2007;32(6):627-34.

4. Olmarker K, Rydevik B, Dahlin LB, Danielsen N, Nordborg C. Effects of epidural and intrathecal application of collagenase in the lumbar spine: an experimental study in rabbits. Spine (Phila Pa 1976). 1987;12(5):477-82

5. Olmarker K, Holm S, Rosenqvist AL, Rydevik B. Experimental nerve root compression. A model of acute, graded compression of the porcine cauda equi- 
na and an analysis of neural and vascular anatomy. Spine (Phila Pa 1976) 1991;16(1):61-9.

6. Olmarker K, Rydevik B, Nordborg C. Autologous nucleus pulposus induces neurophysiologic and histologic changes in porcine cauda equina nerve roots. Spine (Phila Pa 1976). 1993;18(11):1425-32.

7. Olmarker K, Blomquist J, Strömberg J, Nannmark U, Thomsen P, Rydevik B. Inflammatogenic properties of nucleus pulposus. Spine (Phila Pa 1976). 1995;20(6):665-9.

8. Kawakami M, Tamaki T, Hashizume H, Weinstein JN, Meller ST. The role of phospholipase A2 and nitric oxide in pain-related behavior produced by an allograft of intervertebral disc material to the sciatic nerve of the rat. Spine (Phila Pa 1976). 1997;22(10):1074-9.

9. Olmarker K, Rydevik B. Selective inhibition of tumor necrosis factor-alpha prevents nucleus pulposus-induced thrombus formation, intraneural edema, and reduction of nerve conduction velocity: possible implications for future pharmacologic treatment strategies of sciatica. Spine (Phila Pa 1976). 2001;26(8):863-9.

10. Onda A, Murata Y, Rydevik B, Larsson K, Kikuchi S, Olmarker K. Nerve growth factor content in dorsal root ganglion as related to changes in pain behavio in a rat model of experimental lumbar disc herniation. Spine (Phila Pa 1976) 2005;30(2):188-93.

11. Murata Y, Nannmark U, Rydevik B, Takahashi K, Olmarker K. Nucleus pulposusinduced apoptosis in dorsal root ganglion following experimental disc herniation in rats. Spine (Phila Pa 1976). 2006;31(4):382-90.

12. Murata Y, Nannmark U, Rydevik B, Takahashi K, Olmarker K. The role of tumo necrosis factor-alpha in apoptosis of dorsal root ganglion cells induced by herniated nucleus pulposus in rats. Spine (Phila Pa 1976). 2008;33(2):155-62.

13. Grava AL, Ferrari LF, Parada CA, Defino HL. Experimental model to study intervertebral disc herniation. Rev Bras Ortop. 2008;43(4):116-25

14. Möller KA, Johansson B, Berge OG. Assessing mechanical allodynia in the rat paw with a new electronic algometer. J Neurosci Methods. 1998;84(1-2):41-7.
15. Hargreaves K, Dubner R, Brown F, Flores C, Joris J. A new and sensitive method for measuring thermal nociception in cutaneous hyperalgesia. Pain. 1988;32(1):77-88.

16. Kawakami M, Tamaki T, Hayashi N, Hashizume H, Nishi H. Possible mechanism of painful radiculopathy in lumbar disc herniation. Clin Orthop Relat Res. 1998;(351):241-51.

17. Murata Y, Nannmark U, Rydevik B, Takahashi K, Olmarker K. Nucleus pulposus-induced apoptosis in dorsal root ganglion following experimental disc herniation in rats. Spine (Phila Pa 1976). 2006;31(4):382-90.

18. Murata Y, Olmarker K, Takahashi I, Takahashi K, Rydevik B. Effects of lumbar sympathectomy on pain behavioral changes caused by nucleus pulposus-induced spinal nerve damage in rats. Eur Spine J. 2006;15(5):634-40.

19. Tachihara H, Sekiguchi M, Kikuchi S, Konno S. Do corticosteroids produce additional benefit in nerve root infiltration for lumbar disc herniation? Spine (Phila Pa 1976). 2008;33(7):743-7.

20. Knowles RG, Moncada S. Nitric oxide synthases in mammals. Biochem J. 1994;298(Pt 2):249-58.

21. Cunha FQ, Assreuy J, Moss DW, Rees D, Leal LM, Moncada S, et al. Differential induction of nitric oxide synthase in various organs of the mouse during endotoxaemia: role of TNF-alpha and IL-1-beta. Immunology. 1994;81(2):211-5.

22. Wolkow PP. Involvement and dual effects of nitric oxide in septic shock. Inflamm Res. 1998 Apr;47(4):152-66.

23. Moncada S. The L-arginine: nitric oxide pathway, cellular transduction and immunological roles. Adv Second Messenger Phosphoprotein Res. 1993;28:97-9.

24. Tracey WR, Nakane M, Kuk J, Budzik G, Klinghofer V, Harris R, et al. The nitric oxide synthase inhibitor, L-NG-monomethylarginine, reduces carrageenaninduced pleurisy in the rat. J Pharmacol Exp Ther. 1995;273(3):1295-9.

25. Wei XQ, Charles IG, Smith A, Ure J, Feng GJ, Huang FP, et al. Altered immune responses in mice lacking inducible nitric oxide synthase. Nature. 1995;375(6530):408-11. 